\title{
Role of the Venous System in Baroreceptor-Mediated Reflexes in Man
}

\author{
Stephen E. Epstein, G. David Beiser, Morris Stampfer, and Eugene Braunwald \\ From the Cardiology Branch, National Heart Institute, Bethesda, Maryland
}

A B S T R A C T Although baroreceptor stimulation produced by marked alterations in arterial pressure has been shown to produce reflex changes in venous tone in animals, the effects on venous tone in man of altering arterial pressure within the physiologic range have not been clear. In six subjects, venous tone did not change when mean arterial pressure was raised by $25-40 \mathrm{~mm} \mathrm{Hg}$, although heart rate fell reflexly by $40 \%$. Venous tone remained constant in 10 subjects when arterial pressure was lowered. This contrasted to the sustained rise in forearm vascular resistance and the persistent tachycardia that occurred. However, 12 subjects continued to respond to these interventions by transient venoconstriction. To eliminate possible emotional influences on venous tone due to the experimental intervention, venous responses were studied before and during general anesthesia in five of these subjects. In contrast to the response before anesthesia, an equivalent fall in arterial pressure during anesthesia no longer evoked a venoconstrictor response. Venous reactivity and the baroreceptor reflex arc remained intact during anesthesia, since venous tone always rose after a deep inspiration, and tachycardia always accompanied the fall in arterial pressure. It is concluded that changes in arterial pressure in the physiologic range in man do not induce measurable reflex alterations in venous tone, and that the increases sometimes seen with decreases in arterial pressure appear to be due to extraneous psychic factors.

Address requests for reprints to Dr. Eugene Braunwald, Cardiology Branch, National Heart Institute, Bethesda, Md. 20014.

Received for publication 29. May 1967 and in revised form 21 August 1967.

\section{INTRODUCTION}

It has long been recognized that the veins contain a large proportion of the total blood volume and hence function as a capacitance system (1-6). Since small alterations in the size of these capacitance vessels might play an important homeostatic role in the control of cardiac output and arterial pressure, much interest has centered upon the mechanisms responsible for the regulation of the venous bed. One means by which such regulation can be achieved is through baroreceptor-mediated reflexes, and sulsstantial eviclence is available to support the contention that this system plays an important role in the regulation of the degree of venoconstriction. Thus, a number of investigations have demonstrated that a reduction in carotid sinus pressure produces venoconstriction in the dog (7-12), and that carotid sinus hypertension produces venodilation $(7,9,10)$. As a result of such studies, in their monograph Heymans and Neil wrote that "the most important change during reflex systemic hypertension of sino-aortic origin is probably that of venoconstriction" (13).

On the other hand, Browse, Donald, and Shepherd (14) have recently shown that venous tone in dogs is not significantly altered by changes in baroreceptor activity if the range of pressure change incluced in the carotid sinus is kept within physiologic limits; alterations in venous tone occurred only with large variations in carotid sinus pressure. The role of the baroreceptor system in regulating venous tone in man is also clisputed. Thus, upright tilt, lower-body negative pressure, and drug-inluced hypotension have all been shown to be followed by venoconstriction (15-20); on the 
other hand, several recent studies have shown that the venoconstriction after upright tilt and lowerbody negative pressure occurs irregularly and is generally slight and transient (21-23). It has been our experience in studies on conscious man that it is often extremely difficult to determine whether an increase in venous tone after an intervention which decreases baroreceptor activity is truly mediated by the baroreceptor system, or is the result of the well-known responsiveness of the venous system to many sensory and emotional stimuli. This consideration suggested the possibility that the variable results of the earlier studies in man might have been caused by the reaction of the capacitance vessels to stimuli other than those sensed by the baroreceptor system.

In the present investigation an attempt was made to determine whether or not the capacitance system participates in reflexes mediated by the baroreceptor system. Accordingly, venous tone was measured before and during arterial hypertension induced pharmacologically, and arterial hypotension induced pharmacologically and by subatmospheric pressure applied to the body below the iliac crests (lower-body negative pressure). In order to eliminate as completely as possible all extraneous stimuli that might affect venous tone and thereby lead to erroneous interpretations, the following steps were taken.

(a) Each subject was thoroughly familiarized with the experimental procedure and was studied several times until reproducible reactions were elicited.

(b) The response of the veins to arterial hypotension was studied before and during general anesthesia. While the depth of anesthesia used was sufficient to abolish responses to painful and other noxious stimuli, it did not abolish reflex changes in heart rate in response to induced hypotension, or venoconstriction in response to chest wall movement.

\section{METHODS}

21 male and 3 female subjects whose ages ranged from 19 to $54 \mathrm{yr}$ were studied. 11 of the subjects were normal volunteers and 13 were patients with various forms of heart disease in functional classes I-III (New York Heart Association). 4 of the patients had had a StarrEdwards mitral valve prosthesis inserted 6-15 months previously. Before any of the patients were included in the study, it was first determined that each had the usual increase in venous tone in response to such standard stimuli as a deep inspiration, mental arithmetic, or application of ice to the skin $(15,21,24-29)$. Venous tone was measured in each subject by the occluded limb technique recently described in detail by Samueloff, Bevegård, and Shepherd (28). In several subjects forearm venous tone was also measured simultaneously by either the equilibration technique (18) or the acute occlusion method $(17,18,29)$.

\section{A. Occluded Limb Térhique}

Venous pressure was measured through a 19 or 21 gauge scalp vein needle or a small polyethylene catheter introduced percutaneously into a superficial vein of the forearm or hand. The tip of the needle or catheter was used as the zero reference level for venous pressure. A sphygmomanometric cuff was placed at the wrist when a hand vein was used and both above the elbow and at the wrist when a forearm vein was used. The hand or forearm was then isolated from the circulation by the rapid inflation of the cuff to $270-300 \mathrm{~mm} \mathrm{Hg}$. In order to achieve venous pressures less than $20-25 \mathrm{~mm} \mathrm{Hg}$ after occlusion, it was often necesary to empty the veins by elevating the limb above the level of the heart before the cuff was inflated.

\section{B. Equilibration Techinique}

This technique has been described in detail (18) and was performed by placing a sphygmomanometric cuff above the elbow and a Whitney mercury-in-rubber strain gauge plethysmograph at the mid-forearm. Venous pressure was recorded proximal to the strain gauge through a 21 gauge scalp vein needle. The forearm was elevated so that the forearm venous pressure was near zero and failed to decrease with further elevation of the arm. Before any measurements were made, the hand was excluded from the system by inflation of a wrist cuff to suprasystolic levels. The cuff above the elbow was then inflated to $30 \mathrm{~mm} \mathrm{Hg}$, and forearm circumference, as measured by the plethysmograph, and the venous pressure were allowed to equilibrate. Since forearm venous pressure remains stable at $30 \mathrm{~mm} \mathrm{Hg}$ after equilibration, acute alterations in forearm volume, as assessed by changes in circumference, reflect a change in venous tone.

\section{Acute Occlusion Techinique}

With the forearm prepared in the same manner as described for the equilibration technique, the brachial cuff was rapidly inflated to $30 \mathrm{~mm} \mathrm{Hg}$, and forearm blood flow, expressed in $\mathrm{ml} / 100 \mathrm{~g}$ of tissue per minute, was calculated from the rate of change in forearm circumference during venous occlusion $(18,29)$. Venous tone was calculated as the ratio of increase in venous pressure to the increase in forearm volume that occurred during venous occlusion and was expressed in $\mathrm{mm} \mathrm{Hg} / \mathrm{ml}(17,18,29)$. Forearm vascular resistance (FVR) was calculated as the ratio of mean arterial pressure to forearm blood flow, expressed as $\mathrm{mm} \mathrm{Hg} / \mathrm{ml} / 100 \mathrm{~g}$ per minute.

Baroreceptor activity was modified by the following methods. 
(a) With the subjects in the $80^{\circ}$ head-up position phenylephrine $(0.3-0.8 \mathrm{mg} /$ minute $)$ was infused at a constant rate with an infusion pump to raise mean systemic arterial pressure by $25-30 \mathrm{~mm} \mathrm{Hg}$.

(b) With the subjects in the supine position, 25-200 $\mu \mathrm{g}$ of synthetic bradykinin (Sandoz Pharmaceuticals, Hanover, N. J.) was injected intravenously over 5-10 sec to lower mean arterial pressure by $10-30 \mathrm{~mm} \mathrm{Hg}$.

(c) Nitroglycerin was administered sublingually in a dose of $0.4-0.8 \mathrm{mg}$ with the subjects in the $80^{\circ}$ head-up position.

(d) Lower body negative pressure was produced with the subjects supine by placing the lower part of the body from the level of the iliac crests into an airtight box $(22,23,30)$ and decreasing pressure within it to $60 \mathrm{~mm}$ $\mathrm{Hg}$ below ambient barometric pressure. This level of negative pressure was achieved in $60-90 \mathrm{sec}$ and maintained for 5-15 min.

(e) Subjects were tilted in less than $5 \mathrm{sec}$ from the supine to the $80^{\circ}$ head-up position on a standard tilt table. The recording of venous tone, measured by the occluded limb technique, began 1-2 $\mathrm{min}$ before the tilt, and was continued until the subjects were returned to the supine position. The subjects remained in the head-up position for a period of time ranging from 5 to $15 \mathrm{~min}$. The arm in which venous tone was measured was placed on an arm board at right angles to the body in order to maintain a relatively constant relationship to the level of the heart throughout the tilt. The pressure transducer was mounted on the arm board and was thus always approximately at the same level as the tip of the needle from which pressure was measured. Any deviation from zero reference that occurred during the tilt was determined by withdrawing the venous needle at the end of the procedure, repositioning it over the vein from which it had been withdrawn, and repeating the tilt; venous pressure changes measured during the tilt were subsequently corrected for any change from the zero reference point.

$b$
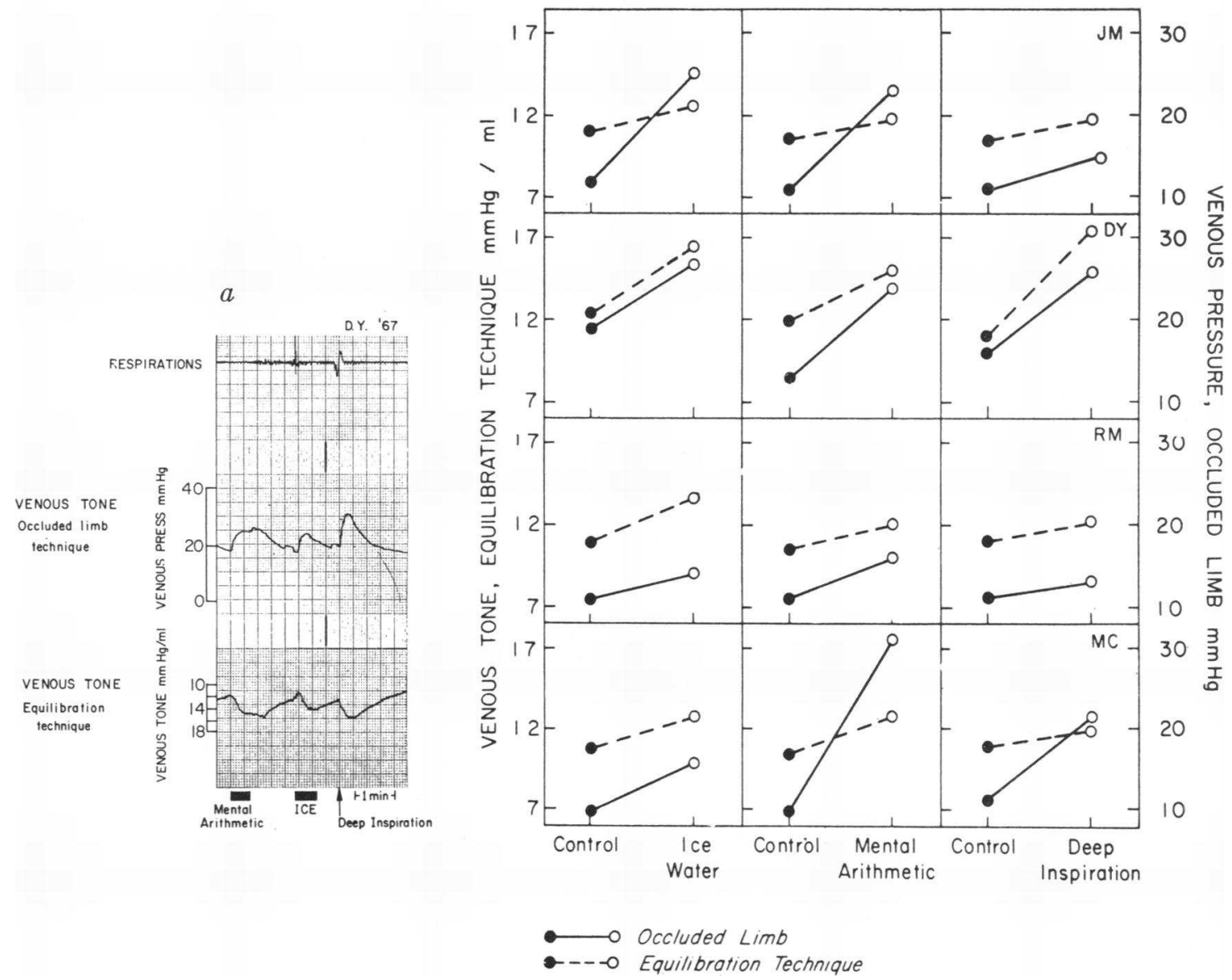

FIGURE 1 The effects on venous tone of ice water placed on the abdomen, mental arithmetic, and deep inspiration, as measured simultaneously by the occluded limb and equilibration techniques (see text). $a$, Recording shows from above downwards: respirations (as recorded by a pneumograph); venous tone (occluded limb technique); venous tonè (equilibration technique). $b$, Venous tone responses obtained from 4 normal subjects. 


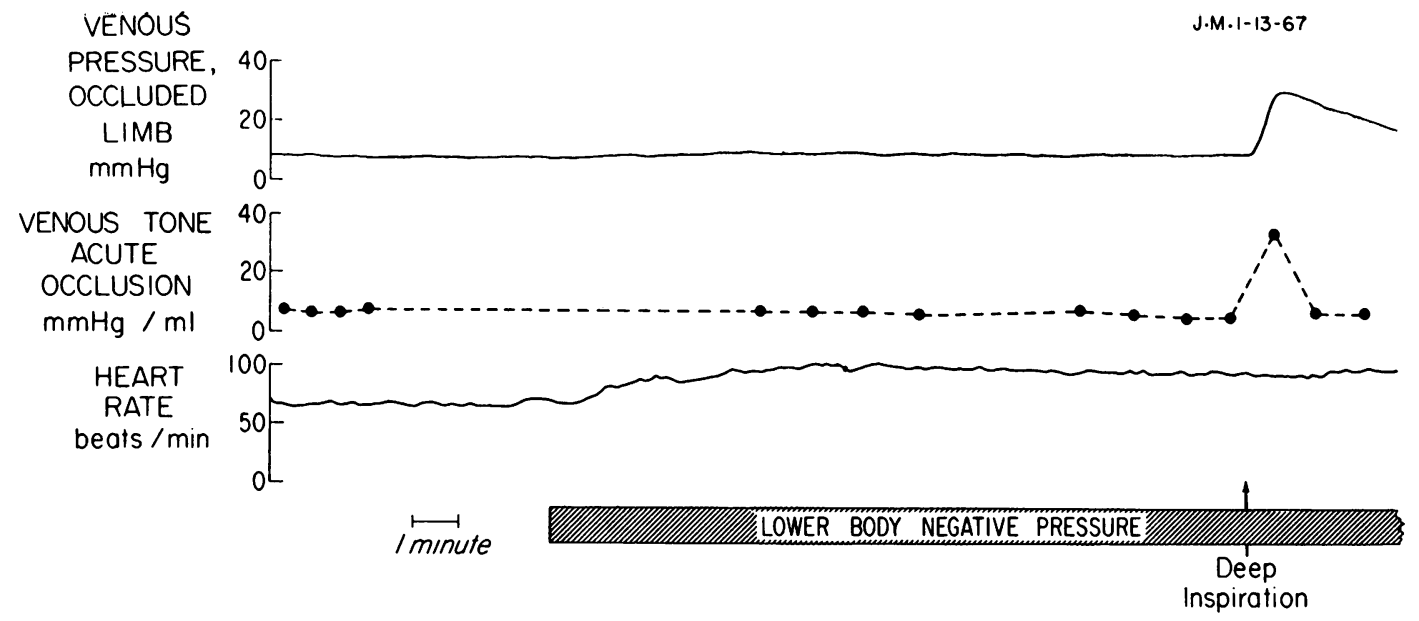

FIgURE 2 The effects on venous tone of deep inspiration and lower body negative pressure, as measured simultaneously by the occluded limb and acute occlusion techniques. Lower body negative pressure causes no change in venous tone as recorded either by the occluded limb or acute occlusion techniques. Reactivity of the veins is shown by the venoconstriction after a deep breath. The increased heart rate that occurs during lower body negative pressure demonstrates that the intervention initiates baroreceptor reflexes.

The studies were performed at a room temperature of $23^{\circ} \mathrm{C}$. All subjects had received a light breakfast before the study, and were thoroughly familiarized with the laboratory and methodology of the study. After placement of the catheters, a deep inspiration was performed to ensure that the venous system was responsive. Depending on the particular experimental protocol, the response of venous tone to several of the following interventions was measured: mental arithmetic; cold stimulation (by immersing the opposite hand in ice water or placing several pieces of ice on the abdomen) ; $80^{\circ}$ head-up tilt; infusion of phenylephrine; injection of bradykinin; sublingual administration of nitroglycerin; or lower body negative pressure.

In five paticnts with atrial fibrillation who were scheduled for elective electrical conversion, the response of venous tone to changes in arterial pressure was studied before and cluring general anesthesia produced by the intravenous injection of sodium thiopental. These patients ranged in age from 37 to $68 \mathrm{yr}$. Three had had a mitral valve prosthesis inserted at least 6 months previously. One had mitral stenosis, and one had arteriosclerotic heart diseasc. Arterial pressure was lowered in four of the subjects by injecting bradykinin and in one by lower body negative pressure. The study during anesthesia was performed before electrical conversion, and venous tone was measured by the occluded limb technique. With this method it was possible to arrest the circulation to the limb under investigation before injection of sodium thiopental and thus obviate any direct effects this agent might have on the reactivity of the veins. In order to ensure that the level of anesthesia did not abolish the ability of the veins to respond reflexly, the venous pressure response of the occluded limb to chest wall movements was tested immediately after the intervention used to lower arterial pressure by producing a moderately deep, forced inspiration.

\section{RESULTS}

I. Comparison of occluded limb with equilibration and acute occlusion techniques for determination of venous tone

The effects of ice placed on the abdomen, mental arithmetic, and deep inspiration were measured simultaneously by the occluded limb and equilibration techniques in four subjects. In all of them each stimulus increased venous tone as measured by both methods (Figs. $1 a$ and $b$ ).

The effects of a deep inspiration and lower body negative pressure were measured simultaneously by the occluded limb and acute occlusion techniques in eight subjects. Similar changes in venous tone were recorded by the two methods in each subject. At no time was a change in venous tone recorcled with one method when such a change was not recorded with the other method (Figs. 2 and 3 ).

\section{Effects of extraneous environmental stimuli on venous tone}

Many examples of venoconstriction were observed in response to extraneous stimuli such as manipulations of the intravenous tubing, injections of saline, sudden noises, the turning on or off of 


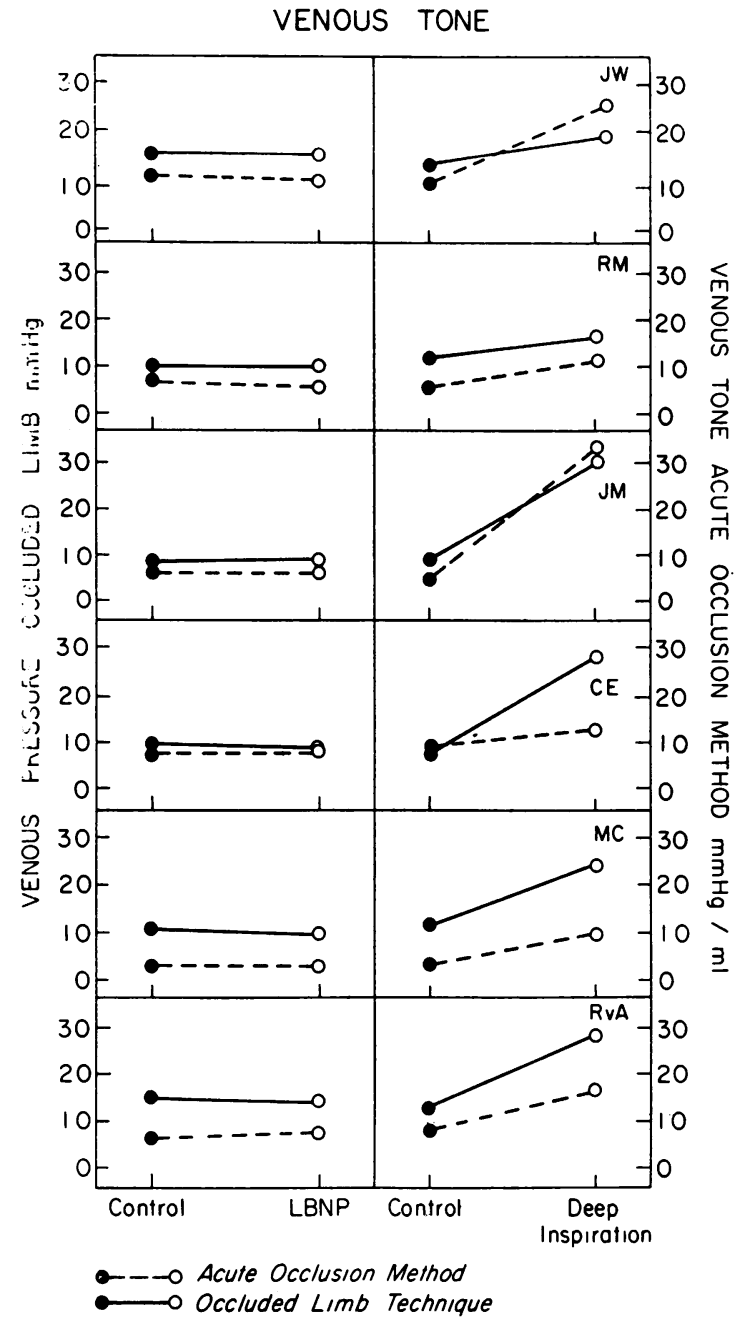

FIgURE 3 The effects on venous tone of lower body negative pressure (LBNP) and deep inspiration as measured simultaneously by the occluded limb and acute occlusion techniques in six subjects. No change in venous tone during LBNP was recorded by either technique. Venous reactivity is demonstrated by the venoconstrictor response to a deep inspiration.

equipment, the presence of a full bladder, the development of a severe headache, or an investigator talking or walking in front of the subject. Fig. 4 shows the effects of a variety of such stimuli on a normal subject.

III. Response of venous tone to elevating systemic arterial pressure

In six subjects at rest in the $80^{\circ}$ head-up position, elevations in mean arterial pressure uniformly resulted in decreases in heart rate; an aver- age increase of $29 \%$ in mean arterial pressure caused an average decrease in rate of $40 \%$. Although this pressure elevation was sufficient to cause pronounced reflex bradycardia, no reflex changes in venous tone were observed in any of the subjects. All the subjects demonstrated venoconstriction with deep inspiration (Figs. 5 and 6).

IV. Response of venous tone to decreasing systemic arterial pressure

\section{A. Conscious Subjects}

1. Bradykinin. The effects on venous tone of the intravenous injection of bradykinin were studied in 12 subjects. In eight of them, venoconstriction occurred consistently. However, in several of these studies the increase in venous tone actually preceded any fall in arterial pressure (Fig. 7), and an injection of saline often produced as much venoconstriction as occurred during the administration of bradykinin. It was thus impossible to determine whether the venoconstriction in these subjects was initiated by a baroreceptor-mediated reflex in response to arterial hypotension, or from the discomfort (local pain, flushing, palpitations, etc.) produced by bradykinin, or whether it resulted from psychic stimuli precipitated by the anticipation of these effects.

In the other four subjects venous tone was unchanged during the hypotension produced by bradykinin (Fig. 8). That the baroreceptor reflex arc was intact in these individuals is attested to by the fact that the fall in arterial pressure was always associated with a marked increase in heart rate; in these four subjects a decrease in mean arterial pressure averaging $19 \%$ was accompanied by a reciprocal increase in heart rate averaging $26 \%$. Reactivity of the venous system was demonstrated in each instance by the increase in venous tone that followed a deep inspiration. While three of these four subjects initially responded to bradykinin by venoconstriction, after one or more experiences with the drug venous tone no longer changed, despite the fact that bradykinin continued to cause comparable decreases in arterial pressure and elevations of heart rate. All these findings suggest that any venoconstriction occurring after bradykinin was due to its side effects rather than to a baroreceptor-mediated reflex resulting from hypotension. 


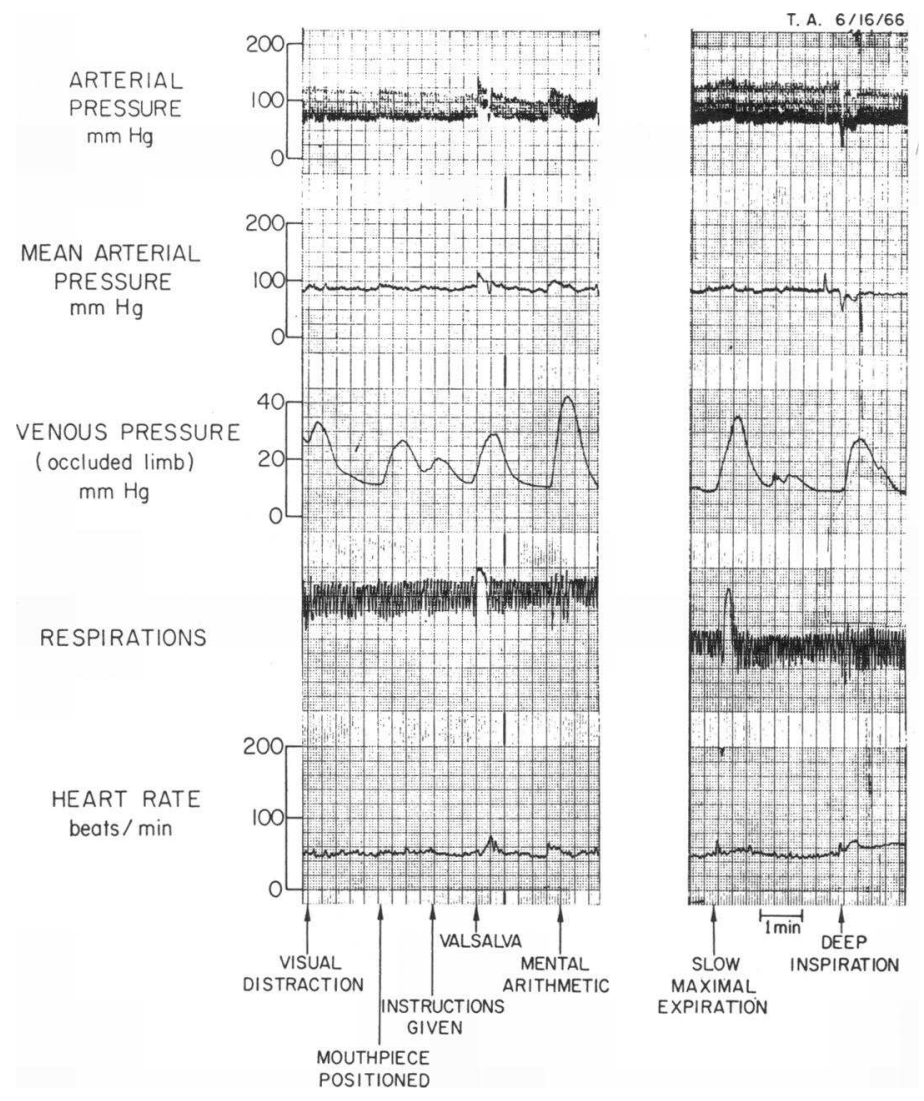

FIGURE 4 The effects on venous tone of various extraneous stimuli.

2. Nitroglycerin. In an attempt to obviate the influence on venous tone of psychic stimuli which might be activated by a sudden reduction in arterial pressure, arterial pressure was lowered gradually in two subjects by the sublingual administration of nitroglycerin. Although the systolic arterial pressure decreased by an average of $17 \%$ and pulse pressure by $30 \%$, no increase in venous tone occurred. That the baroreceptor reflex arc was intact was again demonstrated by the finding of a reciprocal increase in heart rate, averaging $21 \%$. In both subjects venous tone increased in response to a deep inspiration.

3. Lower body negative pressure. Lower body negative pressure produced venoconstriction in 4 of 10 subjects studied and no change in venous tone in 6 as measured simultaneously by the occluded limb and acute occlusion techniques (Figs. 2 and 3 ). Of the subjects who responded with venoconstriction, in several instances venoconstriction occurred immediately after turning on the vacuum pump and clearly preceded the onset of negative pressure. In these individuals venoconstriction could be produced when the pump was turned on even when it was not attached to the pressure box. In four of the six subjects who demonstrated no venoconstriction in response to lower body negative pressure, the initial exposure produced a marked rise in venous tone; subsequent exposures, however, consistently produced no changes in venous tone despite the persistence of reflex tachycardia (Fig. 9). Although these six subjects did not respond to lower body negative pressure with venoconstriction, heart rate increased in all subjects, and venous responsiveness was demonstrated by the venoconstriction that occurred after a deep breath. In addition, forearm vascular resistance was measured in five of the subjects and rose from an average of $29 \mathrm{~mm} \mathrm{Hg}$ / $\mathrm{ml}$ per $100 \mathrm{~g}$ per min to $40 \mathrm{~mm} \mathrm{Hg} / \mathrm{ml}$ per $100 \mathrm{~g}$ per min.

4. $80^{\circ}$ head-up tilt. In each of five subjects 
who were tilted, an increase in venous tone measured by the occluded limb technique commenced within 5-10 sec of the start of the tilt, but returned to base-line values within $3 \mathrm{~min}$. After this initial transient increase, no further elevations in venous tone occurred during the duration of the tilt unless syncopal symptoms developed. In 2 such individuals venous tone began to increase as arterial pressure and heart rate fell precipitously. These changes occurred well after the 12th $\mathrm{min}$ of head-up tilt and were preceded by a period of at least $10 \mathrm{~min}$ during which venous pressure in the occluded limb was equal to that which existed in the supine position.

\section{B. Anesthetized Subjects}

In order to eliminate completely the influence of extraneous psychic stimuli on venous tone, we studied the response of the venous system to arterial hypotension in five patients before and during sodium thiopental anesthesia. Each patient had previously demonstrated a venoconstrictor response to bradykinin (four patients) or lower body negative pressure (one patient) in the unanesthetized state. During anesthesia, however, similar decreases in arterial pressure no longer resulted in venoconstriction. In contrast, anesthesia did not diminish the reflex tachycardia after

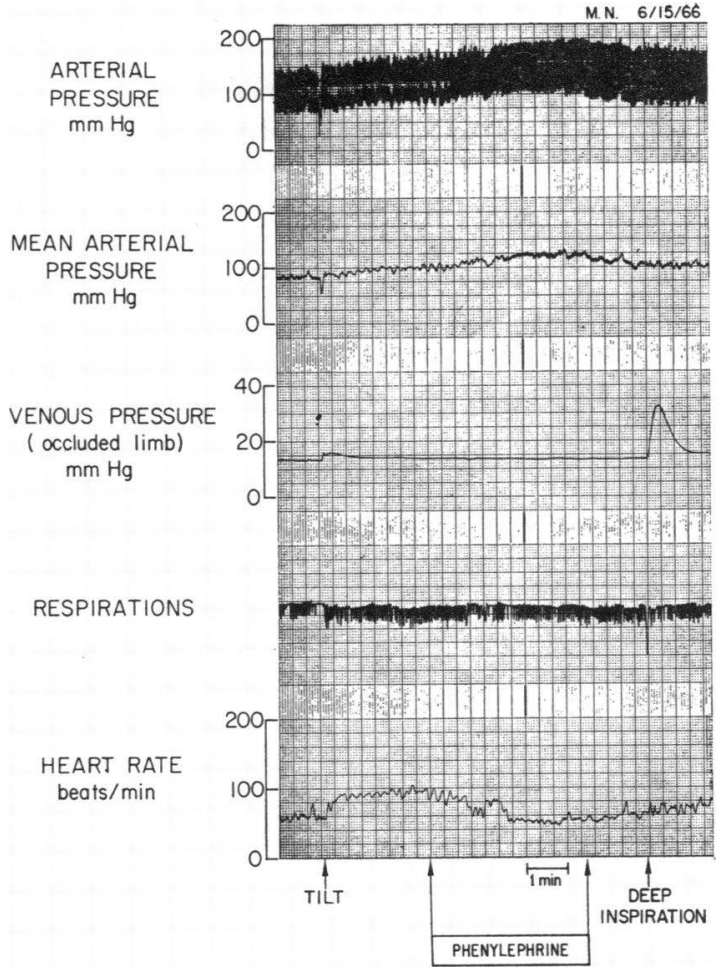

FIGURE 5 Recording obtained from one subject showing the effects of intravenous infusion of phenylephrine. Although arterial pressure rises sufficiently to produce a reflex fall in heart rate, no change in venous tone occurs. A transient increase in venous tone is recorded after tilt from the supine to the $80^{\circ}$ head-up position, and after a deep inspiration.
HEART RATE

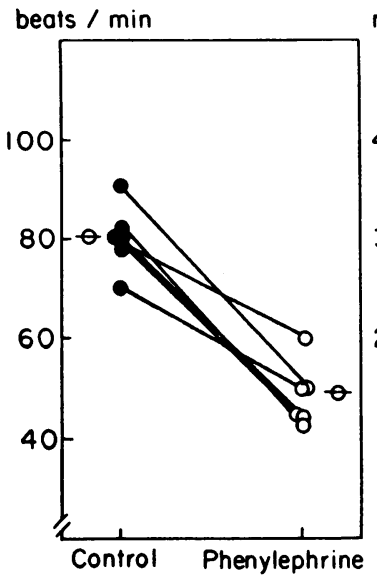

VENOUS PRESSURE, occluded limb

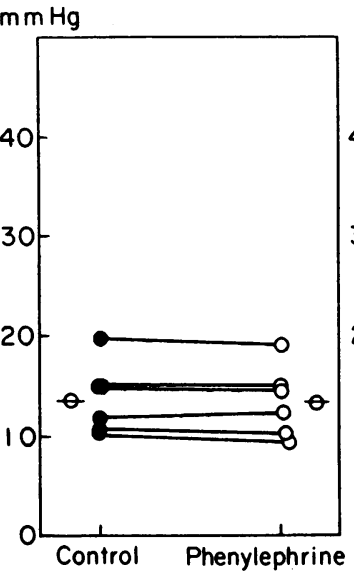

$\mathrm{mm} \mathrm{Hg}$

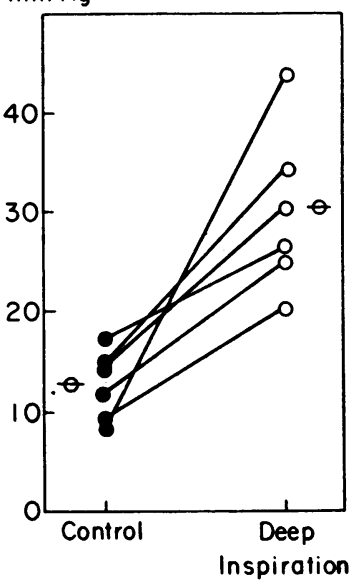

FIGURE 6 The effects of arterial hypertension produced by the intravenous infusion of phenylephrine. No decrease in venous tone occurred despite baroreceptorinduced reflex bradycardia. Venous reactivity is demonstrated by the venoconstrictor response to a deep inspiration. 


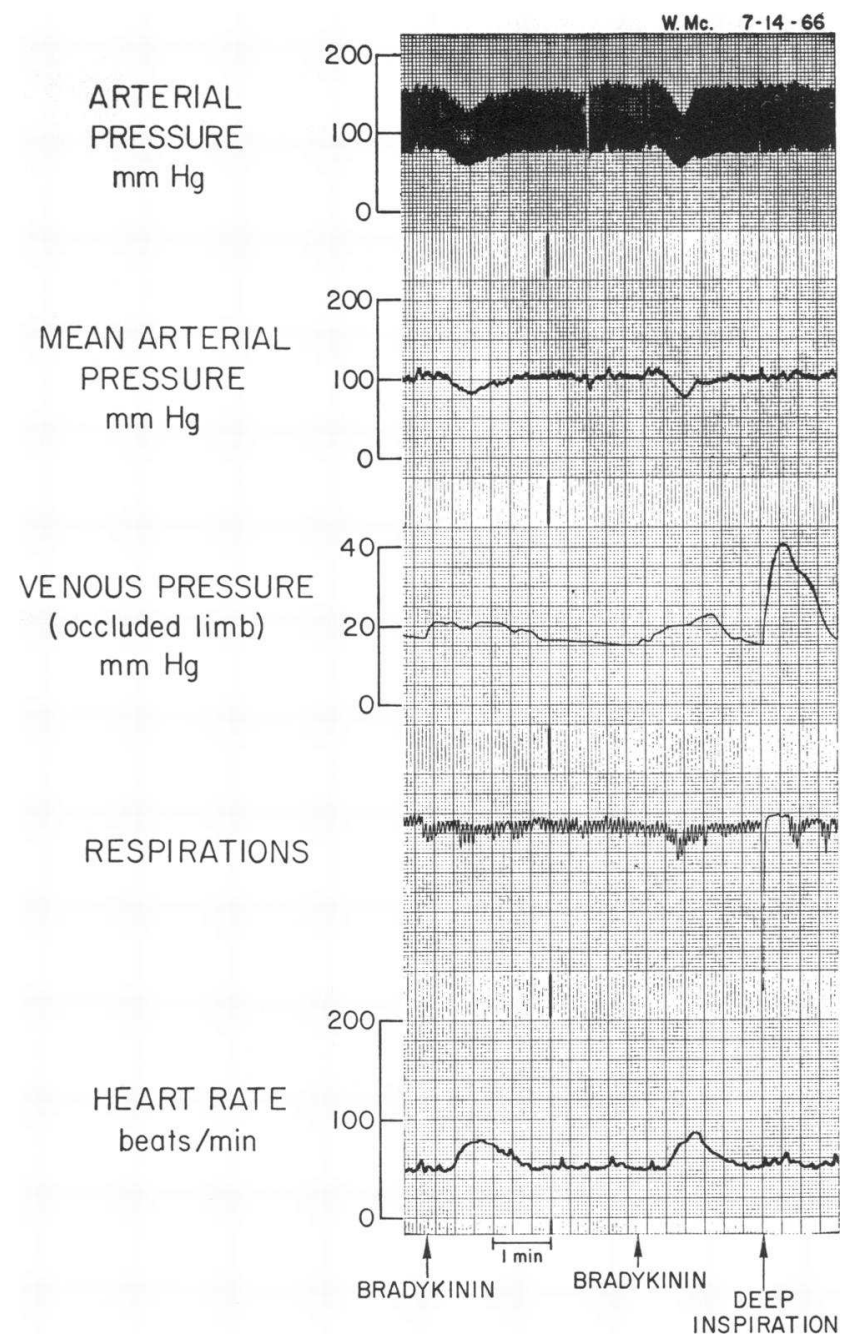

Figure 7 The effects on arterial pressure, venous tone, and heart rate of the intravenous administration of bradykinin. Although an increase in venous tone occurred after bradykinin, the increase began before any discernible fall in arterial pressure.

hypotension, or venoconstriction in response to forced inspiration (Figs. 10 and 11).

\section{DISCUSSION}

The results of this study demonstrate a dissociation between the response to baroreceptor-mediated reflexes of the capacitance vessels on the one hand, and the heart and resistance vessels on the other; when arterial pressure was changed to a degree sufficient to produce reflex alterations in sympathetic discharge to the resistance vessels and to the heart, as manifest by consistent changes in forearm vascular resistance and heart rate, no alterations in venous tone occurred when extraneous psychic stimuli were eliminated. Thus, although it has been generally believed that the veins normally play an important role in baroreceptormediated reflexes, it now appears that the capacitance vessels of the limb do not participate in these reflexes in man when physiologic alterations of baroreceptor stimulation are induced.

Although use of the occluded limb technique as a qualitative measure of changes in venous tone is theoretically acceptable, is technically simple, has been used successfully by several investigators $(20,21,28,31)$, and has been found to show 


\section{HEART RATE}

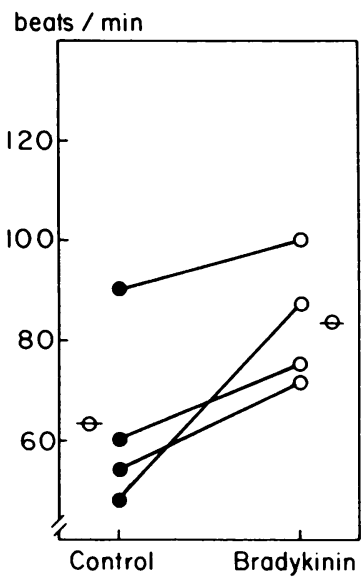

VENOUS PRESSURE, occluded limb

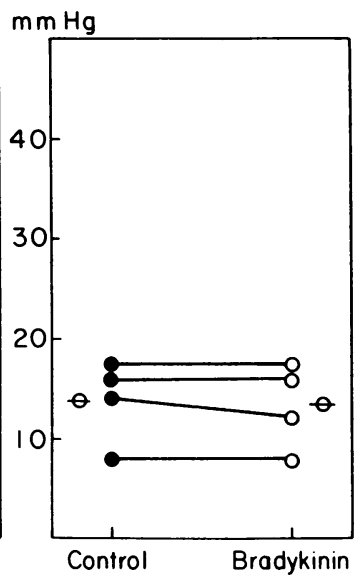

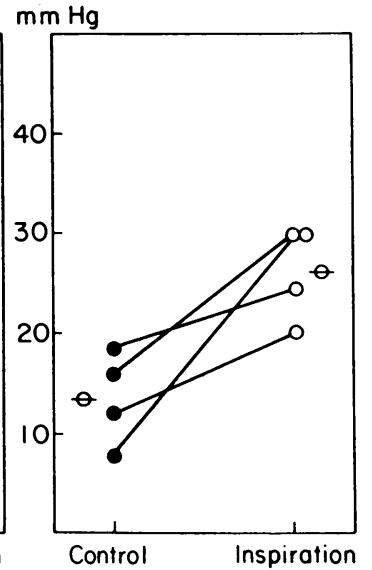

FIGURE 8 The effects of arterial hypotension produced by the intravenous administration of bradykinin in four subjects. No increase in venous tone occurred despite baroreceptor-induced reflex tachycardia. Venous reactivity is demonstrated by the venoconstrictor response to a deep inspiration.
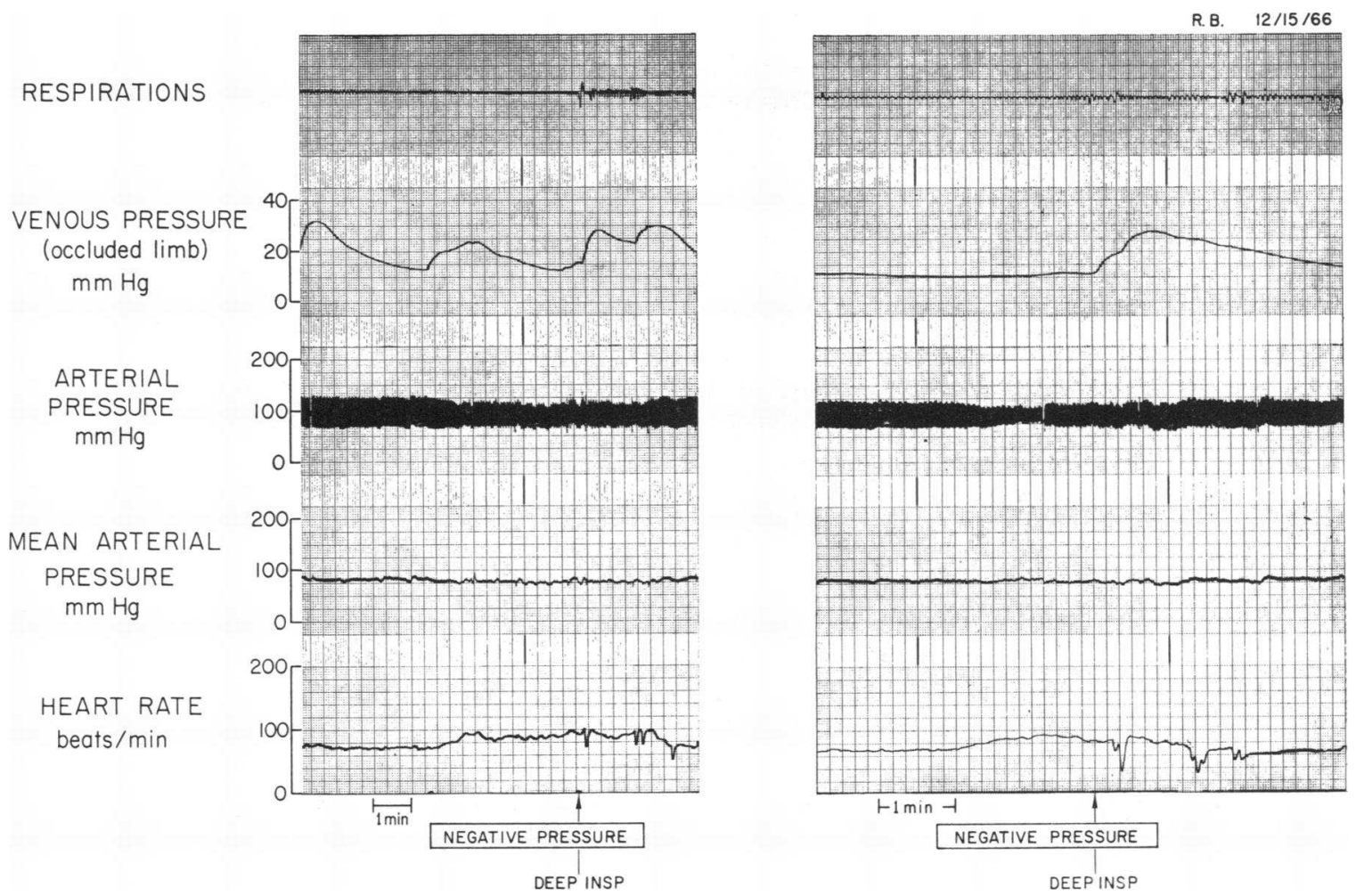

FIGURE 9 The effects on venous tone of two sequential exposures to lower body negative pressure in one subject. The left panel demonstrates the increase in venous tone that occurred after the subject's first exposure. No venoconstriction occurred several minutes later during the second exposure, as demonstrated in the recording at the right. The degree of reflex tachycardia is unchanged during the second exposure, and venous reactivity is shown by the venoconstriction after a deep inspiration. 

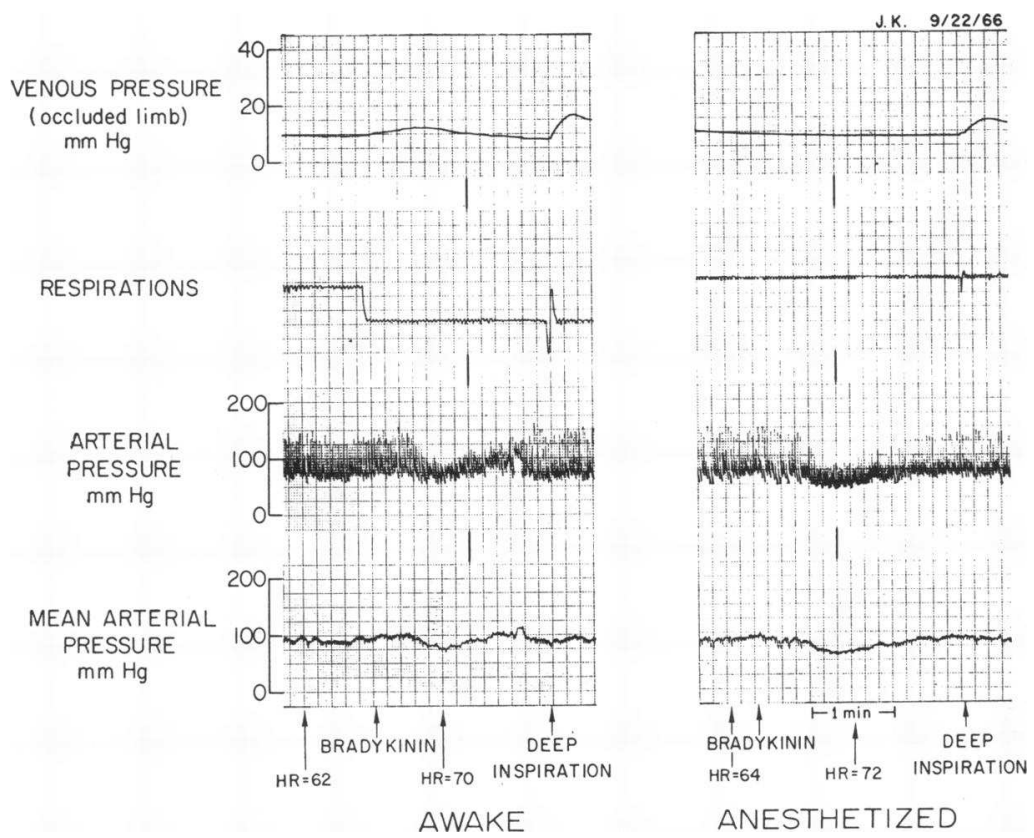

FIGURE 10 The effects of anesthesia in one subject on the venous tone response to a reduction in arterial pressure produced by bradykinin. The left panel shows that while conscious, venoconstriction occurred after bradykinin administration. The right panel demonstrates that after anesthesia no venoconstriction occurred despite a similar decrease in arterial pressure. Anesthesia did not impair the heart rate response to hypotension or the increase in venous tone in response to a forced deep inspiration.

changes in venous tone similar to those found by other methods $(20,21)$, a critical comparison of this technique with more frequently used methods has not heretofore been reported. This is of importance since it is conceivable that changes in the pressure in a superficial vein of an occluded limb may not accurately reflect directional changes occurring in other superficial and/or deep veins. However, when venous tone was measured simultaneously by the occluded limb technique and either the acute occlusion or the equilibration methods, the directional changes in venous tone occurring in response to any of several stimuli were identical, regardless of the method used (Figs. 1-3).

The present investigation also emphasizes the importance in the interpretation of data obtained on the venous bed of recognizing the exquisite sensitivity displayed by the veins to subtle emotional and physical stimuli. For example, the venoconstriction seen in many of the subjects in response to bradykinin, lower body negative pressure, or upright tilt could have been interpreted as demonstrating that the venous system does in fact respond reflexly to changes in arterial pressure. That this was not the case was suggested by the transient nature of the response of the veins to lower body negative pressure and tilting at a time when the increases in heart rate and forearm vascular resistance persisted. Similar findings relating to the transient response of the veins to upright tilt were obtained by Gauer and Thron (21), to lower body negative pressure by Plassaras, Brown, Goei, and Greenfield (22), and to upright tilt and lower body negative pressure by Samueloff, Browse, and Shepherd (23). These latter investigators contrasted the transient response of the capacitance vessels of the limb to the sustained response of the resistance vessels throughout the duration of the stimulation $(23,32)$, a finding confirmed by this investigation. They also observed that if tilting is produced slowly or if lower body negative pressure is gradually increased, the magnitude of the increase in venous tone is diminished.

Although it has been proposed that the response of the veins to baroreceptor stimuli may be delayed 

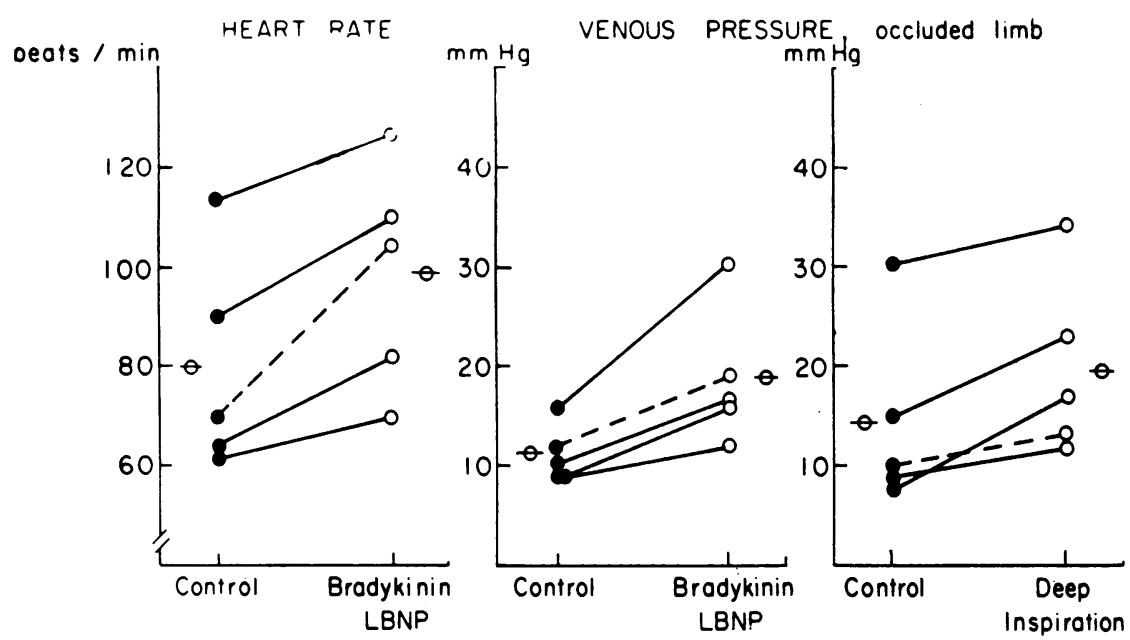

ANESTHESIA
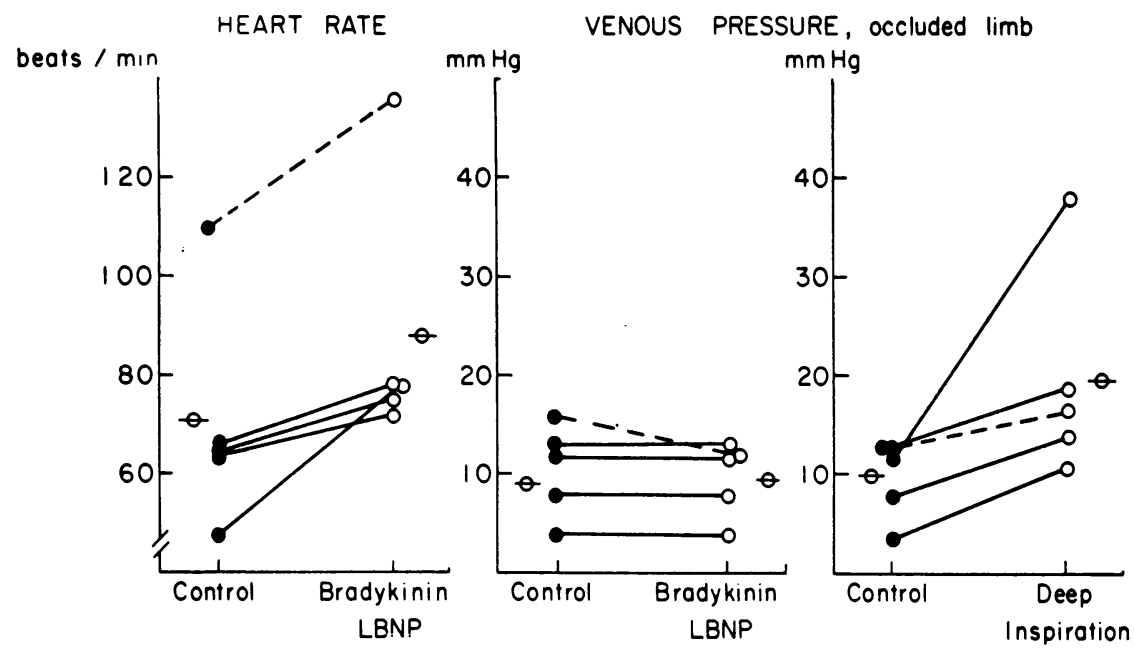

FIgURE 11 The effects of anesthesia on the venous tone response to a reduction in arterial pressure. Upper panels demonstrate that venoconstriction occurred in each subject, while conscious, after a decrease in arterial pressure produced either by bradykinin (solid lines) or lower body negative pressure (LBNP) (broken lines). Lower panels demonstrate that when noxious and psychic stimuli are eliminated by anesthesia, a similar reduction in arterial pressure no longer results in venoconstriction. The reflex tachycardia that occurred during anesthesia suggests that anesthesia did not significantly diminish baroreceptor reflexes, and the venoconstrictor response to a forced deep inspiration demonstrates the unimpaired capacity of the veins to react reflexly.

and require up to 30 min to appear (16), it is apparent that such a delayed response would play no role in the type of rapid compensatory adjustments that are necessary to buffer the effects of the relatively acute alterations in arterial pressure that so often occur during everyday life. It would also be difficult to interpret the cause of the changes in venous tone that take place after so long a period of time, since the duration of the experimental intervention might in itself produce potent psychic stimuli capable of changing venous tone independently of any reflexes mediated by the baroreceptor system.

In addition to the transient nature of the venous 
tone responses to upright tilt and lower body negative pressure, several other observations provide strong evidence against the hypothesis that the increase in venous tone that often occurred after interventions that lowered arterial pressure was due to a baroreceptor-mediated reflex. First, it was observed that the venoconstrictor response disappeared in several subjects after bradykinin had been injected or lower body negative pressure applied several times (Fig. 9). This lack of venous response was seen despite changes in arterial pressure comparable to those initially present when venoconstriction did occur, and contrasted with the changes in heart rate and forearm vascular resistance which were unaltered with repeated interventions. Second, in several subjects in whom venous tone increased during either pharmacologically or mechanically induced reductions in arterial pressure, the increase in venous tone began before any effect on arterial pressure occurred (Fig. 7). Indeed, in many of these subjects an injection of saline or simply turning on the vacuum pump without connecting it to the negative pressure box was sufficient to evoke a venoconstrictor response.

However, although repeated exposure of 10 suljjects to the experimental intervention resulted in the elimination of the venoconstrictor response initially observed cluring bradlykinin administration and lower body negative pressure, 12 subjects continued to respond in such a manner despite repeated exposure. In order to determine whether this venoconstrictor response after either bradykinin injection or lower body negative pressure resulted from psychic stimulation, venous tone responses were studied before and during general anesthesia in a group of patients in whom, while conscious, the intervention leading to arterial hypotension consistently produced an increase in vencus tone. In this way, noxious and psychic stimuli could be eliminated and the response of the capacitance vessels to simple arterial hypotension could be evaluated. When the subjects were anesthetized, in contrast to the response before anesthesia, an equivalent fall in arterial pressure no longer evoked an increase in venous tone (Figs. 10 and 11). Although it could be argued that anesthesia per se was responsible for abolishing reflex responses to arterial hypotension, this seems inlikely in view of the fact that the reflex tachy- cardia occurring with hypotension was undiminished, and the capacity of the veins to react to reflexes that usually evoke venoconstriction was unimpaired.

The hypothesis that the capacitance vessels of the arm do not normally participate in baroreceptor-mediated reflexes is also supported by the work of Bevegård and Shepherd (33) who showed that increasing the transmural pressure across the carotid arteries did not result in a decrease in venous tone. However, since the aortic arch baroreceptors were not exposed to this stimulus, it could be argued that they effectively buffered any reflex changes in venous tone evoked by selective stimulation of the baroreceptors located in the neck. That this was not the case is shown in the present study by the observation that no decrease in venous tone occurred when both the carotid and aortic arch baroreceptors were stimulated simultaneously by the generalized elevation of systemic arterial presure. The effects of systemic hypertension were studied with the subjects in the $80^{\circ}$ head-up position, since it previously has been shown that a significant degree of sympathetic activity is present in this position (34). Hence if alteration of sympathetic activity to the veins were an integral part of the baroreceptormediated reflex, it would be expected that with the subjects in the $80^{\circ}$ head-up position venodilation would have been observed in response to an increase in arterial pressure.

While this study indicates that the veins do not ordinarily participate in baroreceptor reflexes in man it should be emphasized that this conclusion can be applied only to the veins of the limbs, since only these have been studied thus far. In addition, it appears possible that extreme changes in baroreceptor activity, as would occur in cardiogenic shock, massive hemorrhage, syncope, or in individuals subjected to large gravitational stresses such as those induced during centrifugal studies, might lead to changes in venous tone. Indeed, this would appear to be likely if observations on such extreme interventions in the dog are relevant to man.

In conclusion, the results of this investigation suggest that while the venous bed of the human forearm is extremely reactive to a number of stimuli, physiologic alterations in arterial pressure do not in fact produce reflex changes in venous tone. 
It would thus appear that in the face of postural changes, or moderate changes in central blood volume, arterial pressure is maintained relatively constant by alterations in sympathetic outflow to the heart and to the resistance vessels, rather than to the venous bed.

\section{ACKNOWLEDGMENTS}

The authors wish to express their appreciation to $\mathrm{Mr}$. Allen Nimetz and Dr. Barry Silverman for their valuable assistance during many phases of this investigation, and to Dr. John T. Shepherd, who kindly provided plans for construction of the negative pressure box.

\section{REFERENCES}

1. Alexander, R. S. 1963. The peripheral venous system. In Handbook of Physiology. W. F. Hamilton and P. Dow, editors. American Physiological Society, Washington, D. C. 2: 1075.

2. Green, H. D. 1944. Circulation: Physical principles. In Medical Physics. O. Glasser, editor. Year Book Publishers, Chicago. 1: 208.

3. Landis, E. M., and J. C. Hortenstine. 1950. Functional significance of venous blood pressure. Phy'siol. Rev. 30: 1 .

4. Greenfield, A. D. M., and G. C. Patterson. 1956. On the capacity and distensibility of the blood vessels of the human forearm. J. Physiol. (London). 131: 290.

5. Wiedeman, M. P. 1963. Dimensions of blood vessels from distributing artery to collecting vein. Circulation Res. 12: 375.

6. Folkow, B., and S. Mellander. 1964. Veins and venous tone. Am. Heart J. 68: 397.

7. Alexander, R. S. 1954. The participation of the venomotor system in pressor reflexes. Circulation Res. 2: 405.

8. Salzman, E. W. 1957. Reflex peripheral venoconstriction induced by carotid occlusion. Circulation Res. 5: 149.

9. Bartelstone, H. J. 1960. Role of the veins in venous return. Circulation Res. 8: 1059.

10. Ross, J., Jr., C. J. Frahm, and E. Braunwald. 1961. Influence of carotid baroreceptors and vasoactive drugs on systemic vascular volume and venous distensibility. Circulation Res. 9: 75.

11. Gaffney, T. E., W. M. Bryant, and E. Braunwald. 1962. Effects of reserpine and guanethidine on venous reflexes. Circulation Res. 11: 889.

12. Zingher, D., and F. S. Grodins. 1964. Effect of carotid baroceptor stimulation upon the forelimb vascular bed of the dog. Circulation Res. 14: 392.

13. Heymans, C., and E. Neil. 1958. Reflexogenic Areas of the Cardiovascular System. Little, Brown and Co., Boston.
14. Browse, N. L., D. E. Donald, and J. T. Shepherd. 1966. Role of the veins in the carotid sinus reflex. Am. J. Physiol. 210: 1424.

15. P'age, E. B., J. B. Hickam, H. O. Sicker, H. D. McIntosh, and W. W. Pryor. 1955. Reflex venomotor activity in normal persons and in paticnts with postural hypotension. Circulation. 11: 262.

16. Wood, J. E., and J. W. Eckstein. 1958. A tandem forearm plethysmograph for study of acute responses of the peripheral veins of man: The effect of environmental and local temperature change, and the effect of pooling blood in the extremities. J. Clin. Invest. 37: 41.

17. Sharpey-Schafer, E. P. 1961. Venous tone. Brit. Med. J. 2: 1589 .

18. Mason, D. T., and E. Braunwald. 1965. The effects of nitroglycerin and amyl nitrite on arteriolar and venous tone in the human forearm. Circulation. 32: 755.

19. Mason, D. T., and K. L. Melmon. 1965. Effects of bradykinin on forearm venous tone and vascular resistance in man. Circulation Res. 17: 106.

20. Gilbert, C. A., and P. M. Stevens. 1966. Forearm vascular responses to lower body negative pressure and orthostasis. J. Appl. P'hysiol. 21: 1265.

21. Gauer, O. H., and H. L. Thron. 1962. Properties of veins in vivo: Integrated effects of their smooth muscle. Physiol. Rev. 42 (Suppl. 5) : 283.

22. Plassaras, G. C., E. Brown, J. S. Goei, and A. D. M. Greenfield. 1963. Effects of simulated postural blood shifts on the capacity function of the limb vessels. Physiologist. 6: 255.

23. Samueloff, S. L., N. L. Browse, and J. T. Shepherd. 1966. Response of capacity vessels in human limbs to head-up tilt and suction on lower body. J. Appl. Physiol. 21: 47.

24. Duggan, J. J., V. L. Love, and R. H. Lyons. 1953. A study of reflex venomotor reactions in man. Circulation. 7: 869.

25. Burch, G. E., and M. Murtadha. 1956. A study of the venomotor tone in a short intact venous segment of the forearm of man. Am. Heart J. 51: 807.

26. Eckstein, J. W., W. K. Hamilton, and J. M. McCammond. 1958. Pressure-volume changes in the forearm veins of man during hyperventilation. J. Clin. Invest. 37: 956.

27. Merritt, F. L., and A. M. Weissler. 1959. Reflex venomotor alterations during exercise and hyperventilation. Am. Hcart J. 58: 382.

28. Samueloff, S. L., B. S. Bevegård, and J. T. Shepherd. 1966. Temporary arrest of circulation to a limb for the study of venomotor reactions in man. J. Appl. Phy'siol. 21: 341 .

29. Mason, D. T., and E. Braunwald. 1964. Effects of guanethidine, reserpine, and methyldopa on reflex venous and arterial constriction in man. J. Clin. Invest. 43: 1449.

30. Stevens, P. M., and L. E. Lamb. 1965. Effects of lower body negative pressure on the cardiovascular system. Am. J. Cardiol. 16: 506. 
31. Wallace, J. M. 1956. Pressure relationships among arteries and large and small veins. Circulation. 14: 1013.

32. Shepherd, J. T. 1966. Role of the veins in the circulation. Circulation. 33: 484.

33. Bevegård, B. S., and J. T. Shepherd. 1966. Circulatory effects of stimulating the carotid arterial stretch re- ceptors in man at rest and during exercise. J. Clin. Inz'cst. 45: 132.

34. Robinson, B. F., S. E. Epstcin, G. D. Beiser, and E. Braumwald. 1966. Control of heart rate by the autonomic nervous system: Studies in man on the interrelation between baroreceptor mechanisms and exercise. Circulation Res. 19: 400. 